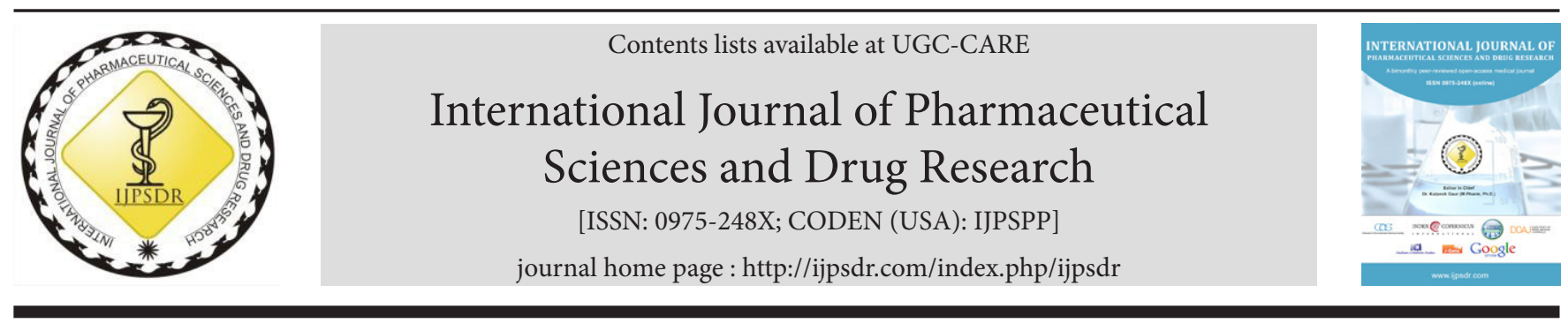

Review Article

\title{
A Comprehensive Review on Self-Nano Emulsifying Drug Delivery Systems: Advancements and Applications
}

\author{
Srikanth Reddy Sokkula ${ }^{1}$, Suresh Gande ${ }^{2^{*}}$ \\ ${ }^{1}$ Career Point University, Kota-325003, Rajasthan, India \\ ${ }^{2}$ Aavyan Labs, Pashamylaram, Hyderabad-502307, Telangana, India
}

\begin{tabular}{l} 
A R T I C L E I N F O \\
\hline Article history: \\
Received: 02 July, 2020 \\
Revised: 24 August, 2020 \\
Accepted: 30 August, 2020 \\
Published: 30 September, 2020 \\
Keywords: \\
Antihypertensives, \\
BCS classification, \\
Excipients, \\
SNEDDS, \\
Solubility. \\
DOI: \\
10.25004/IJPSDR.2020.120522
\end{tabular}

\section{InTRODUCTION TO DRUg SOLUBILITy}

The dissolution of the drug in solvent media is a major factor for the formation of a homogenous system for attaining desired pharmacological activity. The drugs must be in solution form for facilitating absorption at the desired site of action and low solubility limits the drug bioavailability. Poor solubility of drugs also leads to higher doses for achieving therapeutic plasma concentrations post-administration. With 40 to $50 \%$ of novel chemical compounds suffering from low solubility, it remains a challenge for formulation scientists to formulate these drugs into a form that could facilitate maximum bioavailability. ${ }^{[1,2]}$

The Biopharmaceutics Classification System (BCS) catalogs drugs into four different classes based on solubility and intestinal permeability of the drug according to the intestinal drug absorption data provided by the United States Food and Drug Administration (US FDA) (Fig. 1). Drugs possessing lower solubility and high permeability were categorized as class II. The rate-limiting step for these drugs is drug dissolution from formulation and its solubility in gastric fluids but not the rate of absorption. Hence, the enhancement of solubility also enhances drug bioavailability. ${ }^{[3,4]}$

\section{SOLUBILITY ENHANCEMENT TECHNIQUES}

The solubility enhancement follows two strategies; the first one being the development of formulations for increasing speed to the first in-human study without

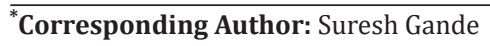

Address: Aavyan Labs, Pashamylaram, Hyderabad-502307, Telangana, India

Email $\square$ : suresh.gande@gmail.com

Tel.: +91-7659825067

Relevant conflicts of interest/financial disclosures: The authors declare that the research was conducted in the absence of any commercial or financial relationships that could be construed as a potential conflict of interest.

Copyright (C) 2020 Srikanth Reddy Sokkula et al. This is an open access article distributed under the terms of the Creative Commons AttributionNonCommercial-ShareAlike 4.0 International License which allows others to remix, tweak, and build upon the work non-commercially, as long as the author is credited and the new creations are licensed under the identical terms.
} 
providing any functional link to these formulations used in clinical trials that can be commercialized, the second approach involves the development of formulations. Various solubility enhancement strategies that mainly involve physical, chemical, or administrative modification of drugs are presented in Fig. 2.

Various techniques adopted by the scientists include reducing the particle size of drug, crystal engineering, the formation of soluble salts of drugs, drug complexing, conversion of amorphous to a crystalline form, supercritical fluid process, use of additives, etc., that alter the physical and chemical characteristics of the drug. Formulation techniques, like lipid nanoparticles, ${ }^{[5]}$ liposomes, ${ }^{[6]}$ and self-emulsifying formulations were also adopted for increasing drug solubility. Selection of method largely depends on the nature of the drug, absorption site, and dosage of the drug.

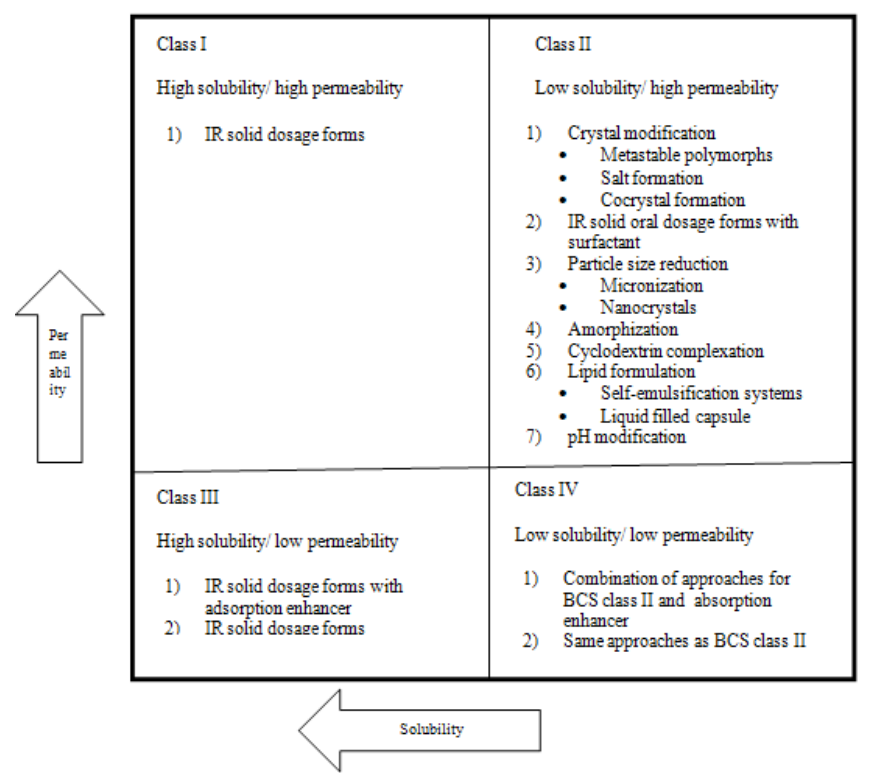

Fig. 1: BCS classification

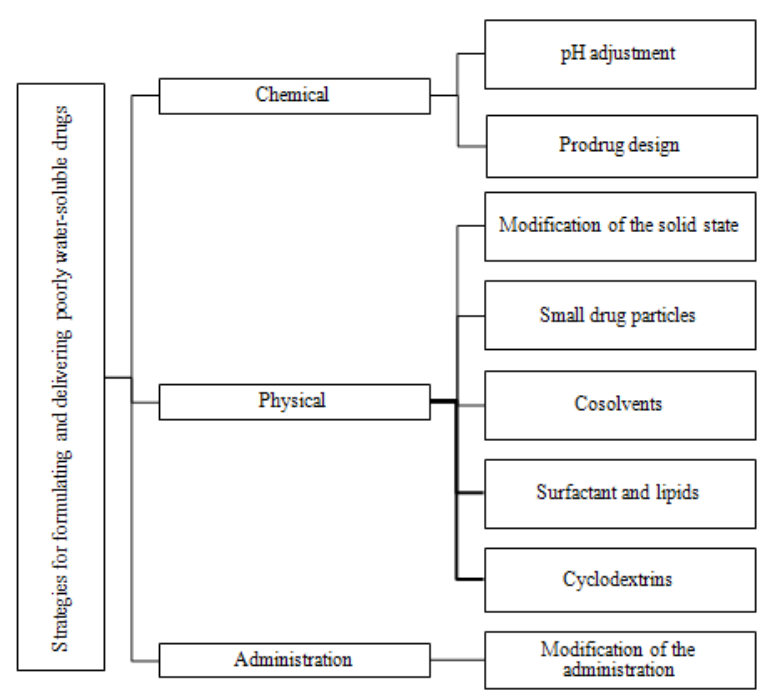

Fig. 2: Techniques employed for solubility enhancement of drugs

\section{Self-EMUlSifying DRUg Delivery SYSTEMS (SEDDS)}

Out of various strategies available to date, SEDDS belonging to lipid-based technique were proved to upsurge drug dissolution rate and assisted the formations of soluble drug phase. These formulations are filled into soft and hard gelatin capsules easily.

The self-emulsifying formulation is an isotropic blend of drug, lipids, surfactants, and co-solvent that generate superfine emulsion on agitation in the gastro intestinal (GI) tract. ${ }^{[7]}$ The SEDDS are categorized into two types, viz., SMEDDS, and SNEDDS, based on globule sizes formed on dispersion. ${ }^{[8]}$

SMEDDS are formulations that produce a transparent microemulsion of oil-in-water or water-in-oil with a globule diameter $<250 \mathrm{~nm}$. SNEDDS possess a droplet size of 20 to $200 \mathrm{~nm}$ that is transparent. [9] SNEDDS is a competent, well-designed, and patient compliant technique for sparingly soluble drugs, as it enhances the solubility, dissolution patterns in the GI tract, increases permeability, and enhances absorption. ${ }^{[10]}$

\section{SNEDDS MECHANISM OF ACTION}

The SNEDDS on administration, followed by gentle agitation arising from gastric movements, forms oilin-water nanoemulsion immediately and impulsively with particles of nanometric range $(<200 \mathrm{~nm})$. These nanoparticles comprising the drug that is previously dissolved in the oil phase provides a superior interfacial surface to facilitate dispersion into GI fluids. ${ }^{[11]}$ This increased interfacial area enhances drug solubility and permeability by altering transport property (Fig. 3). [12]

Nanosize droplets experience rapid digestion followed by quicker absorption of the drug into the GI tract.
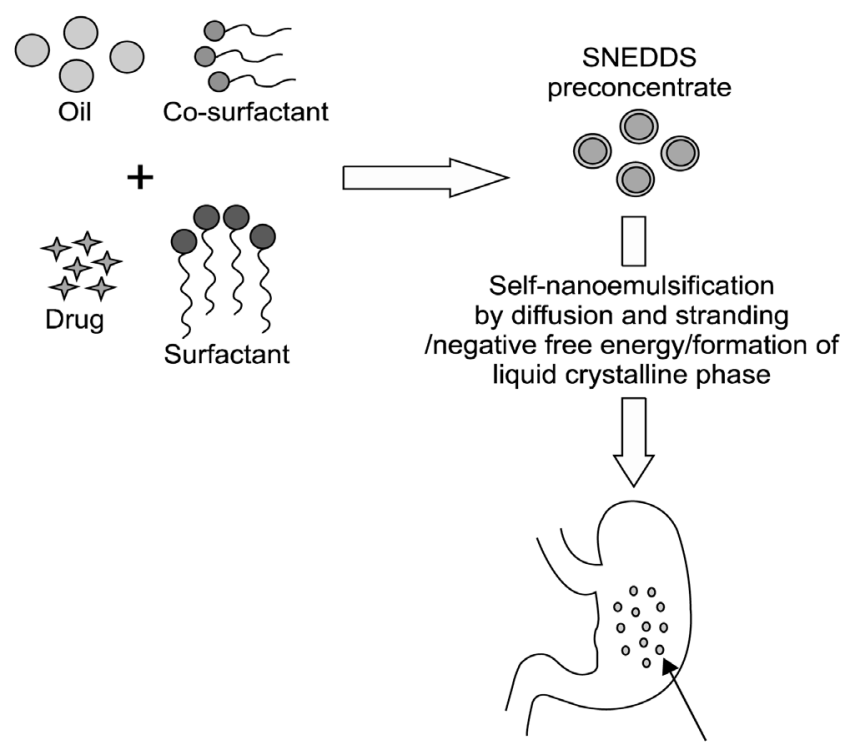

Nanoemulsion formation by slight agitation and aqueous dilution in GIT

Fig. 3: SNEDDS mechanism of action 
SNEDDS dosages range between $25 \mathrm{mg}$ to 2 grams. $^{[13]}$ These are effectively encapsulated as single dosage forms which provide greater stability, palatability, and patient acceptance. ${ }^{[14]}$ They also possess higher drug loading capacity when compared to other lipid-based formulations.

\section{Selection of appropriate Drug Candidates for SNEDDS Formulation}

The challenges faced by a formulator during the formulation of an oral dosage form are to solubilize the drug in the GI tract. SNEDDS improve the rate and scope of drug absorption. SNEDDS approach is applied for BCS class II drugs that suffer from inferior water solubility and bioavailability. ${ }^{[15]}$

Administration of these drugs in form of lipids enhances their bioavailability by bypassing the absorptive barrier of reduced water solubility and illustrate dissolution in GI by transferring to the bile-salt mixed micellar phase, through which absorption happens readily. ${ }^{[16]}$ Properties of the drug, including water solubility, $\log \mathrm{P}$ are not adequate to identify the suitability of lipid-based formulation, as they do not predict the in vivo effects. ${ }^{[17]}$

In SNEDDS formulation, the free energy required for the formation of an emulsion is either little or positive or negative. Hence, emulsification happens impulsively. It is essential for the interfacial structure to illustrate no confrontation against surface shearing such that emulsification takes place. The ease of emulsification may be due to the simplicity of water penetration into a variety of liquid crystalline or gel phases on the droplet surface (Fig. 4). ${ }^{[18]}$

\section{Excipients used in SNEDDS Formulation}

\section{Oils}

The oil is used in SNEDDS formulation for solubilizing the lipophilic drug and ease self-emulsification, to augment the amount of drug passing through the intestinal lymphatic system, thus, enhancing absorption. The longand medium-chain triglycerides (LCT and MCT) with varying saturations are employed. The edible oils are not chosen for SNEDDS formulation owing to their inability to solubilize larger drug concentrations. Hydrolyzed vegetable oils are used due to the formation of superior

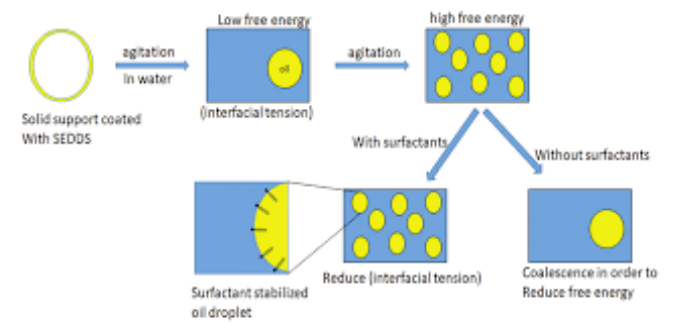

Fig. 4: Energy requisite for emulsion formation emulsification systems with more surfactants accepted for oral administration. They put forward formulation and physiological recompense. New semi-synthetic mediumchain compounds, known as amphiphilic compounds that possess surfactant characteristics, are substituting the oils in SNEDDS. ${ }^{[19,20]}$

\section{Surfactants}

The orally acceptable surfactants are non-ionic that possess higher hydrophilic-lipophilic balance (HLB). Frequently employed emulsifiers, include ethoxylated polyglycolyzed glycerides and polyoxyethylene oleate. Natural emulsifiers are considered safer than synthetic versions but surfactants possess the incomplete selfemulsifying ability. Non-ionic surfactants have lesser toxicity compared to ionic surfactants and direct to enhanced permeability through the intestinal lumen. ${ }^{[21,22]}$

\section{Co-Surfactant}

The SNEDDS formulations require relatively higher concentrations $(>30 \% \mathrm{w} / \mathrm{w})$ of surfactants, which can be condensed by the addition of co-surfactant. These along with surfactants lower the interfacial tension to -ve value, where it expands to form fine droplets, that are consequently adsorbed larger quantities of surfactant and surfactant/co-surfactant till the interfacial tension turns +ve. This process is called "spontaneous emulsification." The addition of co-surfactants into SNEDDS is not obligatory for most non-ionic surfactants. ${ }^{[23]}$ In SNEDDS, the co-surfactants with HLB values ranging between 10 and 14 are used. Hydrophilic co-surfactant is alcohol with medium-chain lengths, including hexanol, pentanol, and octanol that reduce interface between oil and water that facilitate impulsive microemulsion formation (Fig. 5). ${ }^{[24]}$

\section{AdVAnCEMENTS In SNEDdS}

\section{Supersaturated SNEDDS (s-SNEDDS)}

The extent of drug solubility in excipients used for SNEDDS formulation determines the dosage of drug loading. The solubilizing ability of SNEDDS is reduced due to a reduction

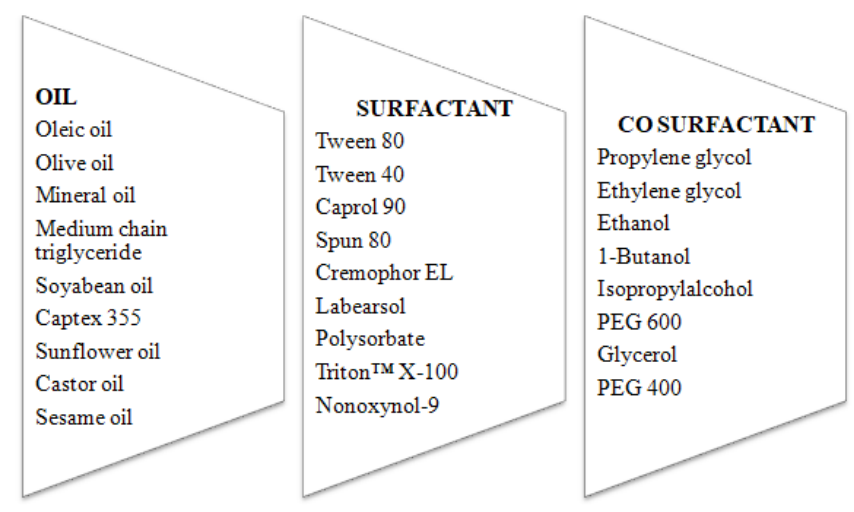

Fig. 5: List of oils, surfactants, and co-surfactants used in SNEDDS formulation 
in lipid content that leads to drug precipitation. Drugs that are highly soluble in surfactants or co-surfactant than lipophilic phase precipitate easily as the solvent ability of these excipients reduces with dilution. Hence, the majority of SNEDDs formulations contain drugs lower than equilibrium solubility. In one, the presence of large amounts of hydrophilic surfactants also facilitates drug precipitation. To overcome this drawback, s-SNEDDS comprising hydrophilic precipitation inhibitors were studied. $^{[25,26]}$

These s-SNEDDS reduce precipitation of drugs in the GI tract by attaining a metastable saturated state. This mechanism involves the assimilation of polymeric precipitation inhibitors (PPIs) that are water-soluble, resulting in prolonged precipitation time in comparison to mean absorption time. Polyvinyl pyrrolidone (PVP), hydroxypropyl methylcellulose (HPMC), sodium carboxymethyl cellulose ( $\mathrm{NaCMC}$ ), and methylcellulose (MC) polymers are some commonly used PPIs. Few drugs precipitate in an amorphous state and demonstrate prominently fast dissolution post precipitation when evaluated in vitro. This indicates that the precipitation of such drugs enhances the bioavailability. Few s-SNEDDS were prepared without the use of PPIs by subjecting the formulations to an alternate "heating and cooling cycle." ${ }^{[27,28]}$

$s$-SNEDDS enhance the stability, concentration $v s$. time profile, drug release rate, the scope of absorption, drug bioavailability, half-life, and feat of hydrophobic and less lipophilic drugs. ${ }^{[29,30]}$ Recently s-SNEDDS for simvastatin ezetimibe, silybin halofantrine, trans-resveratrol, hydrocortisone, and paclitaxel, were reported to exhibit comparatively higher bioavailability.

\section{Solid SNEDDS}

Conservative liquid SNEDDS (L-SNEDDS) are allied with few limitations, like liquid drug-drug interaction, drug-excipients interaction drug precipitation at low temperature, higher cost, delectableness, complex manufacturing, and handling concerns. These limitations are overcome by the solidification of L-SNEDDS. Solid SNEDDS possess enhanced solubility, bioavailability, easier manufacturing procedures, low cost, highly reproducible, higher stability, and scalability. ${ }^{[31]}$ Solid SNEDDS are prepared by adsorption of L-SNEDDS on solid carriers, like aerosil, aeroperl, neusilin, coffee husk, and avicel, using various solidification techniques. ${ }^{[32]}$

\section{Controlled-Release Solid SNEDDS}

SNEDDS pharmacokinetics properties are similar to established oral formulations. They generate rapid absorption resulting in higher $\mathrm{C}_{\max }$, lower $\mathrm{T}_{\max }{ }^{[33]}$ that causes more fluctuations in plasma drug concentration, which need to be closely monitored. Hence, this increases the need for the development of SNEDDS that possess sustained and controlled release properties without conciliation on bioavailability. ${ }^{[34]}$ The sustained release SNEDDS have higher bioavailability, lower $\mathrm{C}_{\max }$, extended mean residence time (MRT) and $\mathrm{T}_{\max }$, and a notable decline in plasma drug instability.

The controlled release of the drug was attained when reconstituted nano-size emulsions were released at zero-order kinetics from the surface orifice of the tablet. The polymers used for controlled release SNEDDS formulations, include HPMC, MCC, poly PLGA, and hydrophobic gelucire. ${ }^{[35]}$

\section{Mucus Permeation SNEDDS}

The mucosal surfaces are roofed with an adhesive mucus layer that enhances the barrier capacity of the mucosa. These mucous barriers are found in the nasal, ocular cavities, lungs, intestines, and vagina. Formulation of mucus gel permeating formulations is a challenging concern. ${ }^{[36]}$ SNEDDS are considered superior mucus permeating nanocarrier. The nanocarriers are believed to cross the mucus layer due to their hydrophobic nature without getting trapped on the layers. The particle size $<50 \mathrm{~nm}$ is most favorable for mucous penetration, as the permeability of any formulation is dependent on size. $^{[36]}$

The study showed that SNEDDS with particle size less than $12 \mathrm{~nm}$ showed maximum permeation of $70 \%$ than $450 \mathrm{~nm}$ with a permeation of $8 \%$. The study also showed that modification of charged surfaces would also enhance penetration. ${ }^{[37]}$ The mucoadhesive polymers used in such formulations include HPMC cremophor RH 40 and triacetin.

\section{Bioactive SNEDDS}

Bio macromolecules, like lipid, protein, and polysaccharide are considered as modern therapeutic agents due to higher specificity and lower toxicity effects. ${ }^{[38]}$ Pharmaceutical research is evolving with various delivery systems for protein, gene delivery, and other biotechnology products. The larger size and low penetrating ability of biomolecules reduce their bioavailability, hence, is a challenge for incorporating them into formulations, which can be overcome by SNEDDS that are proved to enhance solubility, penetration, and bioavailability of molecules incorporated into it.

Sakloetsakun et al. applied insulin/chitosan-TGA SNEDDS formulations for oral drug delivery. They formulated miglyol, cremophor EL, and thiolated chitosanbased SNEDDS for the administration of insulin orally. The formulation displayed an increase in drug release compared to the marketed formulation. The in vivo study also shows an increase in serum insulin than other oral insulin solution. ${ }^{[39]}$ Karamanidou et al. formulated mucus permeating SNEDDS for oral delivery of insulin. The developed formulations have enhanced mucus permeability that was affected by ionic strength. The incorporation of Insulin/Dimyristoyl phosphatidylglycerol 
(INS/ DMPG) in SNEDDS prohibited an early burst release of insulin, hence, considered a promising way for the oral delivery of insulin. ${ }^{[40]}$

\section{Self-Double Nano Emulsifying Drug Delivery Systems (SDEDDS)}

Proteins and the majority of anti-cancer agents cannot be administrated orally as SNEDDS. Studies recommend that SDEDDS that comprises oil-water-oil emulsions are used for the delivery of peptide and protein drugs. ${ }^{[41]}$ SDEDDS are hydrophilic surfactants containing w/o emulsions that produce $\mathrm{w} / \mathrm{o} / \mathrm{w}$ emulsion on dilution with water followed by gentle agitation. SDEDDS preserve peptides and drugs from enzymatic inactivation in gastro intestinal track (GIT), with improved competence and diminished doses.

\section{Targeted SNEDDS}

Improved therapeutic efficacy and reduced toxicity can be achieved by targeted drug delivery. Nanoemulsions remain inside the body for long intervals evading mononuclear phagocytes. Cationic droplets were directed towards an anionic membrane barrier. These formulations are taken up by the liver, thus, aiding targeted delivery. PEGylation is a mechanism, in which polyethelyne glycol (PEG) is connected to a nanodroplet that forms a barrier at the surface, where enzymatic degradation is initiated, thus, increasing stability. ${ }^{[42]}$ HPMC and thiolated chitosan can also be used for the retention of drugs in the GI tract. ${ }^{[43]}$

\section{AdVANTAgE OF SNEDdS ${ }^{[44]}$}

- SNEDDS enhance the bioavailability of the drug, thus, reducing dosage frequency

- SNEDDS enable selective drug targeting towards precise absorption window in GI tract

- They possess higher drug payload

- SNEDDS manage controlled drug delivery profile

- SNEDDS are highly stable formulation and uncomplicated manufacture techniques

- SNEDDS facilitate a larger surface interfacial area for drug partitioning among oil and water

- SNEDDS facilitated wider drug distribution in the stomach and GI tract, thus, reducing the irritation caused by extensive contact among drug and gut walls

- SNEDDS protect the drug from the aggressive environment in the GI tract

- SNEDDS improve the rate and extent of absorption

\section{DISADVANTAgES OF SNEDDS ${ }^{[45]}$}

- The conventional dissolution techniques cannot be applied for SNEDDS as they are dependent on digestion former to dissolution

- The in vitro models of SNEDDS need further research and validation for strength evaluation

- The in vitro-in vivo correlations of SNEDDS must be studied further
- The chemical instability of drugs

- Higher amounts of surfactant used for formulation (30-60\%)

- Higher production cost

- Lower drug incompatibility and stability

- Possibility of drug leakage and precipitation

\section{Potential OF SNEDDS}

The bioavailability enhancement ability of SNEDDS is explained by various in vivo and in vitro methods (Fig. 6). The key discoveries that portray the potentials of SNEDDS are given below.

\section{Enhancing Oral Delivery of Proteins}

Peptides have high hydrophilicity, poor permeability, and less stability in the GI tract, thus, making them inefficient for oral delivery. SNEDDS prove to be a better strategy for improving the absorption of proteins.

The ion-pair suitable for protein are used in formulations to enhance protein lipophilicity and decrease leakage. The protein is also conjugated to phospholipids or lipids to avoid leakage of protein from the formulation. ${ }^{\text {[46-48] }}$

\section{Improved Oral Delivery of Natural Phytochemicals}

Natural phytochemicals that proved to be potential against cancer, arthritis, hepatitis, and suffer from lower water solubility and low metabolic stability. SNEDDS proved to be an alternative method for such phytochemicals for enhanced bioavailability, the therapeutic efficacy of various phytochemicals, including triterpenoids, alkaloids, carotenoids, and hepatoprotective agents. ${ }^{[49]}$

\section{Protection against Biodegradation}

The capability of SNEDDS to diminish drug degradation and enhance drug absorption is advantageous for drugs with low bioavailability. The majority of drugs undergo degradation in the body due to acidity of the stomach, enzymatic degradation, and hydrolytic degradation. These drugs can be protected by incorporating them into

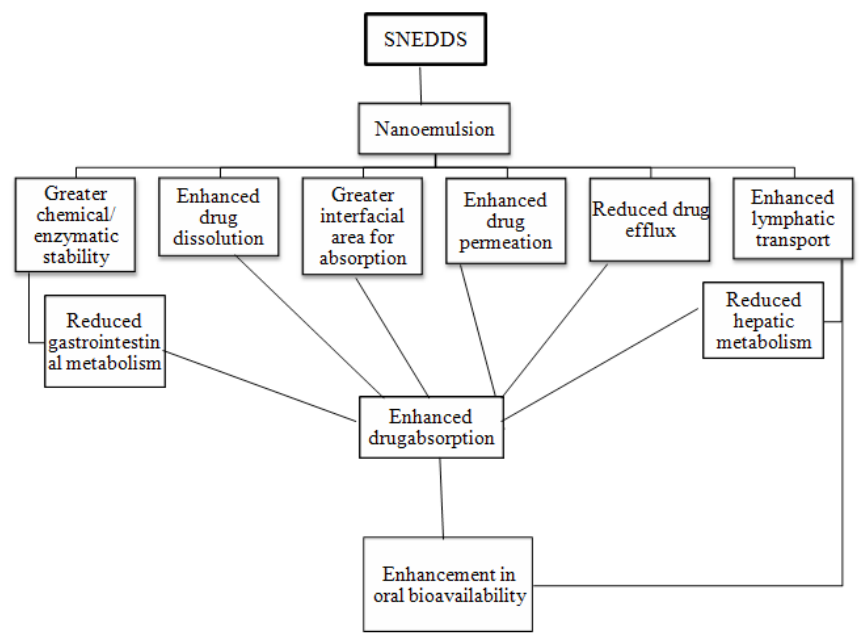

Fig. 6: Potential of SNEDDS 
A Review on Self-nanoemulsifying Drug Delivery System

Table 1: Few SNEDDS formulations of antihypertensive drugs

\begin{tabular}{|c|c|c|c|}
\hline Drug & Excipients & Application & Reference \\
\hline Irbesartan & $\begin{array}{l}\text { Cremophor }^{\circledR} \text { EL Carbitol }^{\circledR} \text {, and } \\
\text { Capryol }^{\circledR} 90\end{array}$ & $\begin{array}{l}\text { About eight times increase in oral bioavailability, } \\
\text { improved dissolution }\end{array}$ & Patel et al., 2011 ${ }^{[54]}$ \\
\hline Telmisartan & $\begin{array}{l}\text { Tween }^{\circledR} 20 \text { Carbitol }^{\circledR} \text {, and } \\
\text { Acrysol }^{\circledR} \text { EL }\end{array}$ & 7.5 folds increase in oral bioavailability & Patel et al., 2011 ${ }^{[55]}$ \\
\hline Talinolol & $\begin{array}{l}\text { M812, P25 MCT, I988, T0106V, } \\
\text { and hydrogenated castor oil }\end{array}$ & $\begin{array}{l}\text { Higher dissolution rate of } 97 \% \text { in } 2 \text { hour with } 4 \text { folds } \\
\text { enhancement in permeability and } 2 \text { folds increase in } \\
\text { oral bioavailability }\end{array}$ & Kazi et al., 2019 ${ }^{[56]}$ \\
\hline Tetrandrine & $\begin{array}{l}\text { Oleic acid SPC and Cremophor } \\
\text { RH- } 40 \text { PEG } 400\end{array}$ & $\begin{array}{l}\text { Drug absorption from SNEDDS is } 3 \text { folds higher than } \\
\text { tablet }\end{array}$ & Liu et al., $2018^{[57]}$ \\
\hline Candesartan & $\begin{array}{l}\text { Capmul PG-8, } \\
\text { Kolliphor EL, and } \\
\text { Transcutol P }\end{array}$ & $\begin{array}{l}\text { Speedy drug dissolution of }>90 \% \text { in } 30 \text { minutes } \\
\text { with } 2 \text { - and } 1 \text {-fold increase in dissolution rate from } \\
\text { SNEDDS }\end{array}$ & Ravinder et al., $2020^{[58]}$ \\
\hline Ramipril & $\begin{array}{l}\text { Capmul PG8, Gelucire 44/14, } \\
\text { and Transcutol P }\end{array}$ & $\begin{array}{l}\text { Formation of thermodynamically stable emulsion } \\
\text { with lowest globule size of } 22.6 \mathrm{~nm} \text { and no drug } \\
\text { precipitation or phase separation }\end{array}$ & Madhavi et al., 2016 ${ }^{[59]}$ \\
\hline Lercanidipine $\mathrm{HCl}$ & $\begin{array}{l}\text { Capmul MCM L8, Tween (R) 80, } \\
\text { and PEG } 400\end{array}$ & Exhibited higher dissolution rates & Venkata et al., 2012 $2^{[60]}$ \\
\hline Valsartan & $\begin{array}{l}\text { Capmul MCM, } \\
\text { surfactant (Labrasol), and co- } \\
\text { surfactant (Tween 20) }\end{array}$ & $\begin{array}{l}3 \text { folds increase in dissolution rate of the drug owing } \\
\text { to enhanced solubility }\end{array}$ & Beg et al., 2012 ${ }^{[61]}$ \\
\hline
\end{tabular}

SNEDDS, which act as a barrier amongst the degrading environment and drug. Drugs, like aspirin, undergo hydrolysis to salicylic acid in the GI tract, thus, degrading. Formulation of this drug into SNEDDS displayed an enhanced plasma profile than normal formulations. The oral bioavailability drug reached $73 \%$ that is much higher than normal formulation. ${ }^{[50]}$

\section{Supersaturable SNEDDS}

The supersaturable SNEDDS are formulated with low amounts of surfactant and polymer for prevention of precipitation by the generation of supersaturated state in vivo. This increases drug solubility and guards the drug against deprivation by cholinesterase in that it is highly adopted for cefpodoxime proxetil (CFP), which posses $\mathrm{pH}$-dependent solubility and the formulation could produce $100 \%$ drug release that is independent of $\mathrm{pH}^{[51]}$

\section{Snedds applied for Enhancement of Bioavailability of Anti-Hypertensive Drugs}

Hypertension, defined as an increase in blood pressure approximately affects 1.13 billion people around the world making it one of the most serious medical conditions. The majority of these drugs possess lower bioavailability, shorter half-life, lower permeability, and undesirable side effects. The effective drug delivery system must include lower dosing frequency, higher bioavailability, more selectivity, and reduced side effects. ${ }^{[52]}$

Traditional oral drug delivery techniques reduce the dosage frequency of antihypertensive drugs, which were previously administered twice or thrice a day. The utilization of chemical-dispensing systems, various technologies, like a polymer-coated bead, transdermal therapeutic systems, osmotic pumps and coat-cores, sodium alginate and spheroidal oral delivery absorption systems, and Geomatrix were applied for these agents with the primary goal of reducing lower blood pressure by continuous drug supply all day long. These sustainedrelease systems suffer from delay the time of achieving the pharmacodynamic effect, posses impulsive bioavailability, suffer first-pass metabolism, experience dosage dumping, persistent toxicity, dose obstinacy, and higher costs.

Nanotechnology is a potential delivery system for sparingly soluble antihypertensive agents by enhancing their solubility and bioavailability. These also lead to the progress of novel hydrophobic entities. The biocompatibility, colloidal size, drug targeting, lowered dose size, reduced toxicity, and patient compliance are some important advantages of nanosystems. SNEDDS provide larger interfacial areas for drug partitioning and bioavailability enhancement, which donors need for higher-energy emulsification, in turn, reducing manufacturing cost. ${ }^{[53]}$ Table 1 lists a few SNEDDS formulations of antihypertensive drugs.

\section{FUTURE PERSPECTIVE}

The advancements in SNEDDS research in the recent past was explored intensively for enhancement of solubility and oral bioavailability of class II drugs. The formulation of liquid SNEDDS to a solid SNEDDS helped to reduce the drug degradation rate but could not eradicate it completely. Therefore, it is vital to recognize microenvironmentmodulation techniques for enhancing the stability of $\mathrm{pH}$-sensitive drugs. The $\mathrm{pH}$ catalyzed and solution-state degradation of drugs in SNEDDS is to be studied. Significant research is being conducted for the conversion of liquid 
SNEDDS to a solid form including tablets and pellets. There exists a necessity to identify an appropriate porous amphiphilic carrier for converting liquid SNEDDS into a solid powder without a major rise in volume and density. The commercialization of SNEDDS depends on the capacity of drug delivery scientists to attend to this aspect of SNEDDS.

\section{REFERENCES}

1. Desai P, Date A, Patravale B. Overcoming poor oral bioavailability using nanoparticle formulations Opportunities and limitations. Drug Discov. 2012;9:87-95.

2. Ohara T, Kitamur S, Kitagawa T. Dissolution Mechanism of Poorly Water Soluble Drug from Extended Release Solid Dispersion System with Ethyl Cellulose and Hydroxypropylmethylcellulose. Int J Pharm. 2005;302(1-2):95-102.

3. Lachman L, Lieberman H, Kanig JL. The Theory And Practise of Industrial Pharmacy. Edn 3 , Lea andFebiger, 1986.

4. 4. Clugston M, Fleming R. Advanced Chemistry. Edn 1, Oxford, UK: Oxford Publishing, 2000.

5. Myrdal PB, Yalkowsky SH. Solubilization of drugs in aqueous media. In: Swarbrick J, editor. Encyclopedia of Pharmaceutical Technology. Edn 3, New York, NY, USA, :Informa Health Care, 2007, pp. 3311.

6. Martin A. Solubility and Distribution Phenomena. Edn 6,Lippincott Williams and Wilkin, 2011.

7. Fatouros DG, Karpf DM, Nielsen FS, Mullertz, A. Clinical studies with oral lipid based formulations of poorly soluble compounds. Ther Clin Risk Manag. 2007;3:591-604.

8. Kale AA, Patravale VB. Design and evaluation of self-emulsifying drug delivery systems. (SEDDS) of nimodipine. AAPS PharmSciTech. 2008;9:191-196.

9. Kang BK, Lee JS, Chon SK, Jeong SY, Yuk SH, Khang G. Development of self-microemulsifying drug delivery systems. (SMEDDS) for oral bioavailability enhancement of simvastatin in beagle dogs. Int J Pharm. 2004;274:65-73.

10. Elgart A, Cherniakov I, Aldouby Y, Domb AJ, Hoffman A. Improved oral bioavailability of BCS class 2 compounds by self nanoemulsifying drug delivery systems. (SNEDDS): the underlying mechanisms for amiodarone and talinolol. Pharm Res. 2013;30: 3029-3044.

11. Shafiq S, Shakeel F,Talegaonkar S. Development and bioavailability assessment of ramiprilnanoemulsion formulation. Eur J Pharm Biopharm. 2007;66:227-243.

12. Shakeel F, Iqbal M, Ezzeldin E. Bioavailability enhancement and pharmacokinetic profile of an anticancer drug ibrutinib by self nanoemulsifying drug delivery system. J Pharm Pharmacol. 2016;68:772-780.

13. Chime S, Kenechukwu F, Attama A. Nanoemulsions-Advances in Formulation, Characterization and applications in drug delivery. Ali DS Application of nanotechnology in drug delivery. Croatia In Tech. 2014; 77-111.

14. Khan AW, Kotta S, Ansari SH. Potentials and challenges in selfnanoemulsifying drug delivery systems. Expert opinion on drug delivery. 2012;9:1305-1317.

15. Singh B, Bandopadhyay S, Kapil R, Singh R,Katare O. Self-Emulsifying Drug Delivery Systems (SEDDS). Formulation development characterization and applications.Crit Rev Thera Drug Carrier Sys. 2009;26:427-521.

16. Colin W,Pouton. Lipid formulations for oral administration of drugs non-emulsifying, self-emulsifying and self-micro emulsifying drug delivery systems. Eur J Pharm Sci. 2000;11(2):93-182.

17. Kohli K, Chopra S, Dhar D, Arora S,Khar RK. Self-emulsifying drug delivery systems.An approach to enhance oral bioavailability.Drug Discov Today. 2010;15(21-22):958-965.

18. Dabros T, Yeung A, Masliyah J,Czarnecki J. Emulsification through area contraction. J Colloid Interface Sci. 1999;210:222-224.

19. Porter CJ, Trevaskis NL,Charman WN.Lipids and lipid-based formulations optimizing the oral delivery of lipophilic drugs.Nat Rev Drug Discov. 2007;6:231-48.

20.Sagar SavaleK. A Review-Self Nanoemulsifying Drug Delivery System (SNEDDS).Int J Chem Pharm Rev Res. 2015;4(6):385-397.

21. GadeAbhishek V, Salunkhe KS, Chaudhari SR, Gadge PB, Dighe GS, AmitAsati.A Review on, Self-Micro Emulsifying Drug Delivery system. Am J Pharmatech Res. 2015;5(1):51-66.

22. Pallavi M, Nigade Swapnil L, Patil Shradha S, Tiwari. Self-Emulsifying Drug Delivery System (SEDDS).A Review. IJPBS. 2012;2(2):42-52.

23. Porter CJ, Trevaskis NL, Charman WN. Lipids and lipid-based formulations optimizing the oral delivery of lipophilic drugs. Nat Rev Drug Discov.2007; 6:231-248.

24. Harman WN, Porter CJ, Mithani S, Dressman JB. Physicochemical and physiological mechanisms for the effects of food on drug absorption the role of lipids and pH. J Pharm Sci. 1997;86:269-282.

25. Mohsin K, Long MA, Pouton CW. Design of lipid-based formulations for oral administration of poorly water-soluble drugs: precipitation of drug after dispersion of formulations in aqueous solution. J Pharm Sci. 2009;98:3582-3595.

26. Do Thi T, Van Speybroeck M, Barillaro V. Formulate-ability of ten compounds with different physicochemical profiles in SMEDDS. Eur J Pharm Sci. 2009;38:479-488.

27. Bandyopadhyay S, Katare O, Singh B. Development of optimized supersaturableselfnanoemulsifying systems of ezetimibe: effect of polymers and efflux transporters. Expert Opin Drug Deliv. 2014;11:479-492.

28. Chen Y, Chen C, Zheng J. Development of a solid supersaturatable selfemulsifying drug delivery system of docetaxel with improved dissolution and bioavailability. Biol Pharm Bull. 2011;34:278-286.

29. 29.Gao P, Akrami A, Alvarez F. Characterization and optimization of AMG 517 supersaturatable self-emulsifying drug delivery system (S-SEDDS) for improved oral absorption. J Pharm Sci. 2009;98:516-528.

30. Thomas N, Holm R, Garmer M. Supersaturated self-nanoemulsifying drug delivery systems (super-SNEDDS) enhance the bioavailability of the poorly water-soluble drug simvastatin in dogs. The AAPS journal. 2013;15:219-227.

31. Kamel AO, Mahmoud AA. Enhancement of human oral bioavailability and in vitro antitumor activity of rosuvastatin via spray dried selfnanoemulsifying drug delivery system. J Biomed Nanotechnol. 2013;9:26-39.

32. Seo YG, Kim DH, Ramasamy T. Development of docetaxel-loaded solid selfnanoemulsifying drug delivery system (SNEDDS) for enhanced chemotherapeutic effect.Int J Pharm. 2013;452:412-420.

33.Zhang X, Yi Y, Qi J. Controlled release of cyclosporine A selfnanoemulsifying systems from osmotic pump tablets: Near zero-order release and pharmacokinetics in dogs. Int J Pharm. 2013;452:233-240.

34. Miao Y, Chen G, Ren L. Characterization and evaluation of self-nanoemulsifying sustained-release pellet formulation of ziprasidone with enhanced bioavailability and no food effect. Drug Deliv. 2014;1-10.

35. Park MJ, Balakrishnan P, Yang SG. Polymeric nanocapsules with SEDDS oil-core for the controlled and enhanced oral absorption of cyclosporine.Int J Pharm. 2013;441:757-764.

36. Patel VF, Liu F, Brown MB. Advances in oral transmucosal drug delivery. Jcontrolled release. 2011;153:106-116.

37. Dünnhaupt S, Kammona O, Waldner C. Nano-carrier systems: Strategies to overcome the mucus gel barrier. Eur J Pharm Biopharm. 2015;96:447-453.

38. Dimitrov DS. Therapeutic proteins. Therapeutic Proteins: Methods and Protocols. 2012;1-26.

39. Sakloetsakun D, Dünnhaupt S, Barthelmes J, Perera G, BernkopSchnürch A. Combining two technologies: Multifunctional polymers and self-nanoemulsifying drug delivery system (SNEDDS) for oral insulin administration. Int JBiolMacromol. 2013;61:363-372.

40. Karamanidou T, Karidi K, Bourganis V, Kontonikola K, Kammona O, Kiparissides C. Effective incorporation of insulin in mucus permeating self-nanoemulsifying drug delivery systems. Eur J 
Pharm Biopharm. 2015;97(Pt A):223-229.

41. Qi X, Wang L, Zhu J. Self-double-emulsifying drug delivery system (SDEDDS): a new way for oral delivery of drugs with high solubility and low permeability. Int J Pharm. 2011;409:245-251.

42. Feeney OM, Williams HD, Pouton CW. 'Stealth'lipid-based formulations: Poly (ethylene glycol)-mediated digestion inhibition improves oral bioavailability of a model poorly water soluble drug. J Controlled Release. 2014;192:219-227.

43. Barthelmes J, Dünnhaupt S, Hombach J. Thiomer nanoparticles: stabilization via covalent cross-linking. Drug Deliv. 2011;18:613-19.

44. Zhao T, Maniglio D, Chen J, Chen B, Motta A, Migliaresi C. Design and optimization of self-nanoemulsifying formulations for lipophilic drugs. Nanotechnology. 2015;26:12510.

45. Krishnaiah YS. Pharmaceutical technologies for enhancing oral bioavailability of poorly soluble drugs.J BioequivAvailab. 2010;2:28-36.

46. Rao SV,Shao J.Self-nanoemulsifying drug delivery systems (SNEDDS) for oral delivery of protein drugs: I. Formulation development. Int J Pharm. 2008;362:2-9.

47. Rao SV, Agarwal P, Shao J.Selfnanoemulsifying drug delivery systems (SNEDDS) for oral delivery of protein drugs: II. In vitro transport study.Int J Pharm. 2008;362:10-15.

48. RaoSV, Yajurvedi K, Shao J.Selfnanoemulsifying drug delivery system (SNEDDS) for oral delivery of protein drugs: III. In vivo oral absorption study.Int J Pharm. 2008;362:16-19.

49. Xi J, Chang Q, Chan CK. Formulation development and bioavailability evaluation of a self-nanoemulsified drug delivery system of oleanolic acid. AAPS PharmSci Tech. 2009;10:172-182.

50. Khan AW, Kotta S, Ansari SH, Sharma RK, Ali J. Potentials and challenges in self-nanoemulsifying drug delivery systems. Expert Opin Drug Deliv. 2012;9(10):1305-1317.

51. Date AA, Nagarsenker MS. Design and evaluation of selfnanoemulsifying drug delivery systems (SNEDDS) for cefpodoximeproxetil. Int J Pharm.2007;329(1-2):166-172.

52. Prisant LM, Elliott WJ. Drug delivery systems for treatment of systemic hypertension. Clin.Pharmacokinet. 2003;42(11): 931-940.

53. Prisant LM, Bottini B, DiPiro JT, Carr AA. Novel drug-delivery systems for hypertension. [Am J Med. 1992;93(2):45S-55S.

54. Patel J, Patel A, Raval M, Sheth N. Formulation and development of a self-nanoemulsifying drug delivery system of irbesartan. J Adv Pharm Technol Res. 2011;2(1):9-16.

55. Patel J, Kevin G, Patel A, Raval M, Sheth N. Design and development of a self-nanoemulsifying drug delivery system for telmisartan for oral drug delivery. Int J Pharm Investig. 2011;1(2):112-118.

56. Kazi M, Al-Swairi M, Ahmad A, Raish M, Alanazi FK, Badran mm,Hussain MD. Evaluation of Self-Nanoemulsifying Drug Delivery Systems (SNEDDS) for Poorly Water-Soluble Talinolol: Preparation, in vitro and in vivo Assessment. Front Pharmacol. 2019;10.

57. Liu C, Lv L, Guo W, Mo L, Huang Y, Li G, Huang X. Self-Nanoemulsifying Drug Delivery System of Tetrandrine for Improved Bioavailability: Physicochemical Characterization and Pharmacokinetic Study. BioMed Res Int. 2018;1-10.

58. RavinderVerma, Deepak Kaushik. Design and optimization of candesartan loaded self-nanoemulsifying drug delivery system for improving its dissolution rate and pharmacodynamic potential. Drug Deliv. 2020;27(1):756-771.

59. Madhavi K,Shikha A,Yadav JK. Self Nano Emulsifying Drug Delivery System Of Ramipril: Formulation And In vitro Evaluation. Int J Pharm Pharm Sci. 2016;8(4):291-296.

60.60. KallakuntaVenkata, Bandari Suresh, JukantiRaju, VeerareddyPrabhakar Reddy. Oral self emulsifying powder of lercanidipine hydrochloride: Formulation and evaluation. Powder Technol. 2012;221:375-382.

61. Beg S, Swain S, Singh HP, PatraChN, Rao ME. Development, optimization, and characterization of solid self-nanoemulsifying drug delivery systems of valsartan using porous carriers. AAPS Pharmscitech. 2012;13(4):1416-1427. 